\title{
NILAI MANFAAT LANGSUNG EKOSISTEM TERUMBU KARANG DI TAMAN WISATA PERAIRAN PADAIDO, PAPUA
}

\author{
Ni’mawati Syariah \\ Program Studi Budidaya Perairan, Fakultas Ilmu-Ilmu Pertanian \\ Universitas Muhammadiyah Gorontalo \\ Email :ni’ma.syariah@umgo.ac.id
}

\begin{abstract}
The aim of the research is to determine the total direct use value of the coral reefs ecosystem in Tourist park Padaido Sea of Biak Numfor Regency. This research used survey method with 244 samples from fishermen as respondents withdrawn with cluster sampling method based on the type of catching tools used a question list to collect data. The total direct use values of coral reefs were analized by calculating direct use value of income fisherman of tourist park are, direct use value of tourism, direct use of coral reef and direct use of research. The results of the research indicated that the total direct use values of coral reef ecosystem of Tourist Park in Padaido sea was $R p$ 180.002.545.756,-/year or Rp 28.814.238,-/ha/year. Direct use value of reef fisheries was $R p$ 14.652.565.556,- lyear or $R p$ 2.345.563,-/ha/year, direct use value of tourism was $R p$ 290.360.000,-/year or $R p$ 46.480,-/halyear, direct use value of coral reef was $R p$ 164.788.180.200,- or $R p$ 26.378.771,-/ha/year and direc use value of research was $R p$ 271.440.000,- or Rp 43.451,-/ha/year.
\end{abstract}

Keywords : Direct Use Values, Coral Reef Ecosystem, Padaido Tourist Park

\begin{abstract}
Abstrak
Penelitian ini bertujuan mengetahui nilai manfaat langsung ekosistem terumbu karang di kawasan Taman Wisata Perairan Padaido, Papua. Jenis penelitian yang digunakan adalah survai dengan sampel 244 nelayan sebagai responden yang dipilih secara cluster sampling berdasarkan jenis alat tangkap dengan menggunakan daftar pertanyaan sebagai alat pengumpulan data. Data dianalisis dengan menjumlahkan nilai manfaat langsung dari ekosistem terumbu karang di kawasan Taman Wisata Padaido. Hasil penelitian menunjukkan bahwa total nilai manfaat langsung ekosistem terumbu karang Taman Wisata Perairan Padaido adalah sebesar Rp 180.002.545.756,-/tahun atau sebesar Rp 28.814.238,-/ha/tahun. Nilai manfaat langsung perikanan terumbu sebesar Rp 14.652.565.556, - atau sebesar Rp 2.345.563/ha/tahun, nilai manfaat pariwisata sebesar Rp 290.360.000,- atau sebesar Rp 46.480,-/ha/tahun, nilai manfaat langsung karang sebesar Rp 164.788.180.200,atau sebesar Rp 26.378.771,- /ha/tahun dan nilai manfaat penelitian sebesar Rp 271.440.000,- atau sebesar Rp 43.451,-ha/tahun.
\end{abstract}

Kata kunci: Nilai manfaat langsung, ekosistem terumbu karang, Taman Wisata Perairan Padaido

\section{PENDAHULUAN}

Memasuki abad ke 21, pembangunan pesisir dan kelautan Indonesia dihadapkan pada beberapa realitas dan kecenderungan ke depan. Beberapa realitas dan kecenderungan ke depan tersebut adalah daya dukung sumber daya di darat dari waktu ke waktu semakin berkurang, sementara jumlah penduduk serta pendapatan masyarakat semakin meningkat. Sebagai konsekuensinya, tuntutan untuk memanfaatkan sumberdaya laut dimasa mendatang akan meningkat. Namun dalam pembangunan sumberdaya pesisir dan kelautan yang berkelanjutan khususnya konservasi selalu dihadapkan pada masalah kebijakan dan investasi dalam sektor tersebut.

Berdasarkan potensi dan keunikannya Kepulauan Padaido pada tahun 2009 Kepulauan Padaido ditetapkan sebagai Taman Wisata Perairan berdasarkan Keputusan Menteri Kelautan dan Perikanan Nomor: KEP.68/MEN/2009 tentang Penetapan Kawasan Konservasi Perairan Nasional Kepulauan Padaido dan Laut di Sekitarnya di Provinsi Papua dengan luas 183.000 ha. Penetapan wilayah Kepulauan Padaido menjadi Kawasan Taman Wisata Perairan pada satu sisi dapat mempertahankan kondisi lingkungan dan sumberdaya kelautan di wilayah ini sehingga manfaatnya dapat diambil 
secara berkelanjutan, sementara pada sisi lain penetapan kawasan tersebut membatasi ruang gerak nelayan yang selama ini memanfaatkan sumberdaya kawasan ini.

Disisi lain pemegang de jure kawasan konservasi (negara) masih sangat miskin data tentang nilai manfaat jasa kawasan konservasi baik kualitatif dan kuantitatif, meskipun fakta berbicara bahwa jasa kawasan konservasi itu jelas keberadaanya dan telah dirasakan. Bila hal ini dibiarkan terus berlarut tanpa adanya upaya penelitian kearah tersebut, dikhawatirkan hal ini menjadi disinsentif bagi upaya pelestarian kawasan konservasi.

Penilaian ekonomi kuantitatif tentang manfaat kawasan konservasi secara keseluruhan diharapkan menjadi cara yang efektif dalam mereduksi pemahaman yang keliru tentang kecilnya nilai ekonomi kawasan konservasi dibandingkan dengan bentuk pemanfaatan lainnya. Pemahaman tentang konsep valuasi memungkinkan para pengambil kebijakan untuk mengelola dan memanfaatkan berbagai sumberdaya alam dan lingkungan pada tingkat yang paling efektif dan efisien serta mampu mendistribusikan manfaat dan biaya konservasi secara adil.

Valuasi ekonomi dapat menjadi suatu instrumen penting dalam peningkatan penghargaan dan kesadaran masyarakat terhadap barang dan jasa yang dihasilkan oleh sumberdaya alam dan lingkungan (Garrod dan Willis, 1999). Ketidaktahuan beberapa pihak terhadap nilai sumberdaya alam dan lingkungan khususnya terumbu karang yang ada di Taman Wisata Perairan Padaido akan menyebabkan pengambilan keputusan yang tidak proporsional dalam pemanfaatannya, bahkan cenderung merusak. Penelitian ini bertujuan untuk mengetahui; total manfaat langsung keberadaan ekosistem terumbu karang di Taman Wisata Perairan Padaido, Papua.

\section{METODE PENELITIAN}

Penelitian ini dilaksanakan di Taman Wisata Perairan Padaido, Kepulauan Padaido yang merupakan salah satu kawasan konservasi perairan di kabupaten Biak Numfor. Populasi dalam penelitian ini adalah semua nelayan yang melakukan penangkapan ikan di Taman Wisata Perairan Padaido. Untuk penetapan responden nelayan yang dijadikan sampel yaitu dengan menggunakan teknik pengambilan cluster sampling, dimana populasi diklasifikasikan dalam beberapa kelompok berdasarkan jenis alat tangkap yang digunakan (Sukardi, 2003). Jumlah responden nelayan adalah sebanyak 244 responden. Sedangkan untuk mengetahui manfaat pariwisata, manfaat penelitian dan manfaat langsung karang dipilih para pengelola wisata, kepala desa, tokoh adat ataupun masyarakat setempat yang dianggap mengetahui informasi yang butuhkan selama melakukan penelitian.

Jenis data yang digunakan adalah data primer dan sekunder. Data primer adalah data yang dikumpulkan melalui kuisioner dan wawancara langsung. Sementara data sekunder adalah data yang berasal dari instansi. Model analisis yang digunakan adalah sebagai berikut:

\section{Manfaat Langsung Ekosistem Terumbu Karang}

Manfaat langsung atau Direct Use Value (DUV) adalah manfaat yang dapat diperoleh dari ekosistem terumbu karang misalnya perikanan terumbu, pariwisata, penelitian, penambangan karang, ikan hias, dan lain-lain (Fauzi, 2002) dengan rumus sebagai berikut:

TML $=$ ML1 + ML2 + ML3 + ML4...+MLn

Keterangan:

TML = Total Manfaat Langsung

ML1 = Manfaat Langsung Perikanan Terumbu

ML2 = Manfaat Langsung Pariwisata

ML3 = Manfaat Langsung Pemanfaatan Karang

ML4 =Manfaat Langsung Penelitian

Total manfaat langsung (TML) adalah penjumlahan seluruh manfaat dan fungsi langsung terumbu karang di Taman Wisata Perairan Padaido Kabupaten Biak Numfor.

\section{HASIL DAN PEMBAHASAN}

Dari hasil penilaian yang telah dilakukan ekosistem terumbu karang Kawasan Taman Wisata Perairan Padaido memiliki beberapa nilai manfaat langsung yaitu manfaat langsung perikanan terumbu, manfaat langsung pariwisata, manfaat langsung penggunaan batu karang, dan manfaat langsung penelitian. Berdasarkan perhitungan total nilai manfaat 
langsung dari ekosistem terumbu karang di Taman Wisata Perairan Padaido sebesar Rp 180.002.545.756,-/tahun atau sebesar $\mathrm{Rp}$ 28.814.238,-/ha/tahun. Nilai manfaat langsung perikanan terumbu sebesar Rp 14.652.565.556, - atau sebesar Rp 2.345.563/ha/tahun, nilai manfaat pariwisata sebesar Rp 290.360.000,; atau sebesar $\mathrm{Rp} 46.480$,-/ha/tahun, nilai manfaat langsung karang sebesar Rp 164.788.180.200,- atau sebesar Rp 26.378.771,- /ha/tahun dan nilai manfaat penelitian sebesar $\mathrm{Rp} 271.440 .000,-$ atau sebesar Rp 43.451,-ha/tahun.

Besarnya nilai ekonomi manfaat langsung perikanan terumbu karang mengindikasikan bahwa masyarakat sekitar Taman Wisata Perairan Padaido sangat merasakan secara langsung manfaat dari terumbu karang. Adapun hasil dari setiap nilai manfaat langsung ekosistem terumbu karang
Taman Wisata Perairan Padaido dapat dilihat berikut ini;

\section{Manfaat Langsung Perikanan Terumbu di TWP Padaido}

Penduduk di kawasan TWP Padaido umumnya merupakan nelayan yang terdiri atas 744 RT nelayan yaitu 590 RT nelayan dari 454 KK di wilayah Distrik Padaido dan 154 RT nelayan dari 479 KK di wilayah Distrik Aimando yang memanfaatkan sumberdaya perikanan terumbu dengan menjalankan aktivitas-aktivitas perikanan diantaranya: 1) Jaring insang, 2) pancing, 3) alat tangkap lain (Tombak, Speargun/tembak, Sumpit, Penikam, Bubu, Bom dll), 4) Rumput laut dan 5) pencari kerang. Adapun nilai manfaat langsung perikanan terumbu untuk wilayah Distrik Padaido dapat dilihat pada Tabel 1.

Tabel 1. Nilai manfaat langsung perikanan terumbu di TWP PadaidoWilayah Distrik Padaido

\begin{tabular}{|c|c|c|c|c|c|c|c|c|c|}
\hline No & $\begin{array}{l}\text { Jenis } \\
\text { usaha } \\
\text { Perikanan }\end{array}$ & $\begin{array}{r}\text { Jml } \\
\text { Spl }\end{array}$ & $\begin{array}{c}\mathrm{Jml} \\
\mathrm{Pls}\end{array}$ & $\begin{array}{l}\text { Pendapatan } \\
\text { Kotor Rata- } \\
\text { rata }(\mathrm{Rp})\end{array}$ & $\begin{array}{r}\text { Pengeluaran } \\
\text { Rata-rata } \\
(\mathrm{Rp})\end{array}$ & $\begin{array}{r}\text { Pendapatan } \\
\text { Bersih } \\
\text { Rata-rata } \\
(\mathrm{Rp})\end{array}$ & $\begin{array}{r}\text { Total } \\
\text { Pendapatan } \\
\text { Kotor }(\mathrm{Rp})\end{array}$ & $\begin{array}{r}\text { Total } \\
\text { Pengeluaran } \\
(\mathrm{Rp})\end{array}$ & $\begin{array}{r}\text { Total } \\
\text { Pendapatan } \\
\text { Bersih (Rp) }\end{array}$ \\
\hline 1 & $\begin{array}{l}\text { Jaring } \\
\text { Insang }\end{array}$ & 61 & 610 & 14.916 .885 & 6.168 .607 & 8.748 .279 & 9.099 .300 .000 & 3.762 .850 .000 & 5.336 .450 .000 \\
\hline 2 & Pancing & 51 & 509 & 9.910 .025 & 5.633 .431 & 4.276 .593 & 5.044 .202 .475 & 2.867 .416 .569 & 2.176 .785 .907 \\
\hline 3 & $\begin{array}{l}\text { Rumput } \\
\text { Laut }\end{array}$ & 10 & 15 & 6.657 .500 & 5.262 .500 & 1.395 .000 & 99.862 .500 & 78.937 .500 & 20.925 .000 \\
\hline 4 & $\begin{array}{l}\text { Alat } \\
\text { Tangkap } \\
\text { Lainnya }\end{array}$ & 13 & 189 & 20.703 .462 & 3.955 .385 & 16.748 .077 & 3.912 .954 .231 & 747.567 .692 & 3.165 .386 .538 \\
\hline 5 & $\begin{array}{l}\text { Pencari } \\
\text { Kerang }\end{array}$ & 59 & 590 & 2.247 .500 & 23.778 & 2.223 .722 & 1.326 .025 .000 & 14.028 .889 & 1.311 .996 .111 \\
\hline \multicolumn{2}{|c|}{$\begin{array}{l}\text { Total } \\
\text { pendapatan/Thn }\end{array}$} & 195 & 1913 & 54.435 .371 & 21.043 .700 & 33.391 .671 & 19.482 .344 .206 & 7.470 .800 .650 & 12.011 .543 .556 \\
\hline
\end{tabular}

Sumber : Data Primer yang sudah diolah (2012)

Hasil perhitungan menunjukkan bahwa pendapatan bersih rata-rata dari usaha perikanan di Taman Wisata Perairan Padaido untuk wilayah Distrik Padaido adalah sebesar Rp 12.011.543.556,-/tahun. Sementara untuk nilai manfaat langsung perikanan terumbu untuk wilayah Distrik Aimando dapat dilihat pada Tabel 2. Dari Tabel 2 dapat terlihat bahwa pendapatan bersih rata-rata dari usaha perikanan di Taman Wisata Perairan Padaido untuk wilayah Distrik Aimando adalah sebesar Rp 2.641.022.000,-/tahun. Jadi total manfaat langsung dari hasil perikanan di Taman Wisata Perairan Padaido adalah sebesar $\mathrm{Rp}$ 14.652.565.556,-/tahun atau sebesar $\mathrm{Rp}$ 2.345.536,./Ha/tahun.

\section{Manfaat Langsung Pariwisata}

Kawasan wisata bahari di Kepulauan Padaido seperti di Pulau Wundi, Ureb, Pasi, Mbromsi, Dauwi, Meosmangguandi, Yeri dan Pakreki dengan objek wisata adalah wisata bahari dan rekreasi pantai, khususnya di Pulau Wundi selain wisata alam dan rekreasi juga ada wisata dengan objek wisata sejarah (Taman Bahari).

Nilai manfaat langsung pariwisata dari ekosistem terumbu karang di perairan Kepulauan Padaido dapat dihitung dengan menggunakan metode travel cost yaitu dengan menghitung biaya yang dikeluarkan oleh para wisatawan selama berada di pulau, baik itu biaya perjalanan, biaya penginapan, biaya makan dan biaya lainnya. Berdasarkan data diperoleh banyaknya wisatawan (baik 
wisatawan asing dan domestik) yang berkunjung adalah sebesar 28 orang dengan rata-rata lama tinggal selama 3 hari (Dinas Pariwisata Kabupaten Biak Numfor, 2012).
Perhitungan tersebut menghasilkan manfaat langsung potensi pariwisata dan rekreasi Taman Wisata Perairan kepulauan Padaido sebesar Rp 290.360.000,-/tahun.

Tabel 2. Nilai manfaat langsung perikanan terumbu di TWP Padaido Wilayah Distrik Aimando

\begin{tabular}{|c|c|c|c|c|c|c|c|c|c|}
\hline No & $\begin{array}{l}\text { Jenis usaha } \\
\text { Perikanan }\end{array}$ & $\begin{array}{r}\text { Jml } \\
\text { Spl }\end{array}$ & $\begin{array}{r}\text { Jml } \\
\text { Pls }\end{array}$ & $\begin{array}{r}\text { Pendapatan } \\
\text { Kotor Rata- } \\
\text { rata (Rp) } \\
\end{array}$ & $\begin{array}{r}\text { Pengeluaran } \\
\text { Rata-rata } \\
(\mathrm{Rp}) \\
\end{array}$ & $\begin{array}{r}\text { Pendapatan } \\
\text { Bersih Rata- } \\
\text { rata (Rp) } \\
\end{array}$ & $\begin{array}{r}\text { Total } \\
\text { Pendapatan } \\
\text { Kotor (Rp) } \\
\end{array}$ & $\begin{array}{r}\text { Total } \\
\text { Pengeluaran (Rp) }\end{array}$ & $\begin{array}{r}\text { Total } \\
\text { Pendapatan } \\
\text { Bersih (Rp) }\end{array}$ \\
\hline 1 & Jaring Insang & 5 & 48 & 14.840 .000 & 8.954 .000 & 5.886 .000 & 712.320 .000 & 429.792 .000 & 282.528 .000 \\
\hline 2 & Pancing & 25 & 250 & 9.044 .720 & 4.160 .500 & 4.884 .220 & 2.261 .180 .000 & 1.040 .125 .000 & 1.221 .055 .000 \\
\hline 3 & $\begin{array}{l}\text { Alat Tangkap } \\
\text { Lainnya }\end{array}$ & 5 & 53 & 20.162 .000 & 4.457 .000 & 15.705 .000 & 1.068 .586 .000 & 236.221 .000 & 832.365 .000 \\
\hline 4 & $\begin{array}{l}\text { Pencari } \\
\text { Kerang }\end{array}$ & 15 & 154 & 2.010 .000 & 29.000 & 1.981 .000 & 309.540 .000 & 4.466 .000 & 305.074 .000 \\
\hline Tot: & pendapatan/thn & 50 & 505 & 46.056 .720 & 17.600 .500 & 28.456 .220 & 4.351 .626 .000 & 1.710 .604 .000 & 2.641 .022 .000 \\
\hline
\end{tabular}

Sumber : Data Primer yang sudah diolah, 2012.

\section{Manfaat Langsung Karang}

Pemanfaatan batu karang di Taman Wisata Perairan Padaido, Papua, umumnya bisa di bedakan atas 2 jenis yaitu pemanfaatan yang dikonsumsi langsung dalam bentuk kapur sirih dan pemanfaatan dalam hal pondasi rumah penduduk. Berdasarkan perhitungan terlihat bahwa nilai pemanfaatan langsung batu karang sebagai sirih kapur adalah sebesar Rp 223.920.000,-/tahun. Dari hasil perhitungan diperoleh nilai pemanfaatan batu karang sebagai bahan bangunan adalah sebesar $\mathrm{Rp}$ 2.181.000.000,-/tahun.

Cesar (1977) menjelaskan bahwa pengambilan terumbu karang diperkirakan memberikan keuntungan bersih sebesar US\$ $121,000 / \mathrm{Km}^{2}$ karang yang diambil. Bila diperhitungkan dengan kurs saat ini maka nilai tersebut sebesar Rp1,210,000,000,-/ $\mathrm{km}^{2}$ karang (Rp10,000,/US\$). Hal ini tetap diperhitungkan karena dalam penelitian kemungkinan ada masyarakat di TWP Padaido yang menambang karang untuk diperjualbelikan baik itu untuk bahan bangunan maupun karang hias tetapi tidak teridentifikasi, dengan melihat tingginya harga batu karang yang digunakan untuk bahan bangunan di Papua yaitu Rp3.000/bijinya sehingga untuk menghindari terjadinya undervalue, maka keuntungan penambangan karang secara individual tetap diperhitungkan. Dengan demikian maka manfaat langsung karang dapat dihitung dengan memperhitungkan seluruh luasan pulau-pulau yang ada di kawasan TWP Padaido dikali dengan harga batu karang perbijinya di Papua. Berdasarkan hal tersebut diketahui bahwa total luasan seluruh pulau-pulau di kawasan TWP Padaido di estimasi $\pm 134,18562 \mathrm{Km}^{2}$, sehingga dapat dihitung nilai manfaat langsung karang Kawasan Taman Wisata Perairan Padaido yang belum teridentifikasi adalah sebesar Rp 162.364.600.200,-/tahun. Dengan demikian total nilai manfaat langsung karang pada Kawasan Taman Wisata Perairan Padaido adalah sebesar Rp 164.769.520.200,-/tahun.

Menurut Cesar dalam Hasmin (2006) besarnya nilai kerugian yang harus ditanggung oleh masyarakat dari Coral Mining atau penambangan karang sangat besar yaitu dari sektor perikanan sebesar $87.000 \mathrm{US} \$ / \mathrm{km}^{2}$, perlindungan pantai sebesar $10.226 \mathrm{US} \$ \mathrm{~km}^{2}$, pariwisata secara lestari sebesar 3.450 US $\$ \mathrm{~km}^{2}$, dan kerugian lainnya termasuk keanekaragaman hayati sebesar >67.000 $\mathrm{US} \$ \mathrm{~km}^{2}$, dengan total kerugian sebesar $167.830 \mathrm{US} \$ \mathrm{~km}^{2}$, yang apabila disetarakan rupiah, total kerugiannya sebesar Rp 1.678.300.000/ $/ \mathrm{km}^{2}$, sehingga apabila dikalikan dengan luas keseluruhan seluruh pulau-pulau di Taman Wisata Perairan Padaido (134,18562 $\mathrm{km}^{2}$ ), maka total kerugian yang harus ditanggung masyarakat dari penambangan karang adalah sebesar 134,18562xRp $1.678 .300 .000 / \mathrm{km}^{2}=\operatorname{Rp} 225.203 .726 .046,-$ /tahun. Dari nilai ini dapat terlihat bahwa kerugian dari penambangan karang masih jauh lebih besar dibanding manfaat yang dihasilkannya.

\section{Manfaat Langsung Penelitian}

Hasil wawancara dengan pengelola pada kawasan dan masyarakat setempat di ketahui bahwa yang melakukan penelitian pada tahun 2011-2012 di Taman Wisata Perairan Kepulauan Padaido sebanyak 29 orang yang terdiri dari dosen program (S2 \& S3), mahasiswa (S1), dan LSM dengan rata-rata berada di pulau selama 5 hari. Berdasarkan 
kunjungan tersebut dapat diketahui bahwa besarnya biaya-biaya yang dikeluarkan selama penelitian antara lain biaya penginapan, biaya makan dan biaya lainnya, maka rata-rata biaya per peneliti (minimal 1 kali kunjungan) sebesar $\mathrm{Rp}$ 9.360.000,-. Dari hasil perhitungan diketahui total manfaat langsung penelitian pada Taman Wisata Perairan Padaido sebesar Rp 271.440.000,-./tahun.

\section{Total Nilai Ekonomi Manfaat Langsung}

Total nilai ekonomi manfaat langsung ekosistem terumbu karang di TWP Padaido merupakan hasil penjumlahan dari kelima jenis manfaat langsung yang ada dan dapat dilihat pada Tabel 3. Total nilai ekonomi manfaat langsung ekosistem terumbu karang di Taman Wisata Perairan Padaido merupakan hasil penjumlahan dari kelima jenis manfaat langsung yang ada diperoleh hasil sebesar $\mathrm{Rp}$ 180.002.545.75,-/tahun, dengan nilai terbesar berasal dari manfaat langsung karang dengan persentase sebesar $91,55 \%$ kemudian manfaat langsung perikanan terumbu sebesar $8,14 \%$, kemudian manfaat langsung pariwisata sebesar $0,16 \%$, sedangkan manfaat langsung yang memberikan kontribusi terendah adalah manfaat langsung penelitian sebesar $0,15 \%$.

Tabel 3. Total nilai manfaat langsung ekosistem terumbu karang di TWP Padaido

\begin{tabular}{|c|c|c|c|c|}
\hline No & Jenis Manfaat & Nilai (Rp/Thn) & Nilai (Rp/Ha/Thn) & Persentase $(\%)$ \\
\hline 1 & ML Perikanan Terumbu & 14.652 .565 .556 & 2.345 .536 & $8,14 \%$ \\
\hline 2 & ML Pariwisata & 290.360 .000 & 46.480 & $0,16 \%$ \\
\hline 3 & ML Karang & 164.788.180.200 & 26.378 .771 & $91,55 \%$ \\
\hline 4 & ML Penelitian & 271.440 .000 & 43.451 & $0,15 \%$ \\
\hline & Total Manfaat Langsung & 180.002 .545 .756 & 28.814 .238 & $100,00 \%$ \\
\hline
\end{tabular}

Sumber : Data Primer yang sudah diolah (2012)

\section{KESIMPULAN}

Total nilai manfaat langsung Taman Wisata Perairan Padaido adalah 180.002.545.756,-/tahun atau sebesar Rp 28.814.238,-/ha/tahun. Yaitu nilai manfaat langsung perikanan terumbu sebesar $\mathrm{Rp}$ 14.652.565.556, atau sebesar $\mathrm{Rp}$ 2.345.563/ha/tahun, nilai manfaat pariwisata sebesar Rp 290.360.000, atau sebesar Rp 46.480,-/ha/tahun, nilai manfaat langsung karang sebesar Rp 164.788.180.200,- atau sebesar $\mathrm{Rp}$ 26.378.771,- /ha/tahun dan nilai manfaat penelitian sebesar Rp 271.440.000,atau sebesar Rp 43.451,-ha/tahun Keberadaan kawasan konservasi laut Taman Wisata Perairan Padaido perlu dipertahankan keberadaannya, karena bersifat investasi untuk manfaat yang lebih besar di masa mendatang. Dilihat dari sektor perikanan, khususnya manfaat perikanan terumbu karang di Taman Wisata Perairan Padaido potensinya banyak, tetapi belum terkelola secara optimal sehingga perlu pengelolaan yang lebih terarah dan berkelanjutan.

\section{DAFTAR PUSTAKA}

Cesar, H. 1996. Economic Analysis of Indonesian Coral Reefs. The World Bank

Burke, Lauretta, et.al. 2002. Terumbu Karang Yang Terancam Di Asia Tenggara (Ringkasan Untuk Indonesia). Publikasi dalam www.google.com, diakses tanggal 16 Desember 2011.

Dinas Pariwisata Biak. 2012. Daftar Kunjungan Wisatawan di Kabupaten Biak.

Fauzi, A. 2002. Valuasi ekonomi sumberdaya pesisir dan lautan. Makalah pada Pelatihan Pengelolaan Sumberdaya Pesisir dan Lautan. Semarang: Universitas Diponegoro.

Garrod, G. and Willis, K.G. 1999. Economic Valuation of the Environment: methods and case studies, Edward Elgar, Cheltenham.

Hasmin. 2006. Penilaian Ekonomi Ekosistem Terumbu Karang di Perairan Pulau 
Kapoposang, Sarappo Keke dan Saugi Kabupaten Pangkep. Tesis Pascasarjana

PT Arenco Centra. 2011. Monitoring Kesehatan Terumbu Karang TWP Padaido, Biak. Coremap II.

Sukardi. 2003. Metodologi Penelitian Pendidikan, Kompetensi dan Praktiknya. Bumi Aksara, Yogyakarta.

White, A.T. dan A. Cruz-Trinidad. 1998. The Values of Philippine Coastal Resources: Why Protection and Management Are Critical (Cebu City, Philippines: Coastal Resource Management Project). 